\title{
CERVIZ: UNA TRADUCCIÓN ERRÓNEA
}

\author{
Juan José Barcia Goyanes
}

Catedrático de Anatomía de la Universidad de Valencia

\section{RESUMEN}

Una palabra hebrea damente por cervix en todas las ediciones en latín del Libro Sagrado a partir de la Vulgata y por cerviz o sus equivalentes en las lenguas modernas. Ello ha llevado a estereotipar la locución pueblo de dura cerviz aplicada a los hebreos como expresión de los reproches de Jehová ante su rebeldía. Pretendemos demostrar en este trabajo que tales palabras en su equivalente hebreo no han sido pronunciadas nunca, ya que la traducción de çoref debe ser otra. Cuál sea ésta es lo que aquí se pretende elucidar.

\section{SUMMARY}

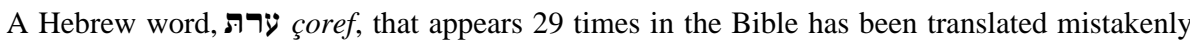
by cervix in all its Latin editions starting from the Vulgata, and for «cerviz» or its equivalent ones in the modern languages. This work seeks to demonstrate that, in fact, such words have never been pronounced in its equivalent one Hebrew, since the çoref translation should be another.

Es harto conocido el dicho italiano traduttore, traditore. El trasladar una idea concebida en una lengua determinada a otra diferente es muy difícil y de aquí que se piense que al hacerlo es casi inevitable el desvirtuar en alguna medida el sentido de aquélla.

Si ello es así, hay sin embargo casos en que la idea del traductor se separa no en un matiz, sino plenamente del sentido de lo traducido. Esto es lo que ha ocurrido con el término hebreo ער çoref* lo que ha tenido como consecuencia que se aplique al pueblo judío un calificativo atribuido a Jehová que en realidad no existió jamás y exponer la historia de este error es el objeto de este trabajo.

Tropecé por vez primera con la palabra çoref al estudiar los hebraísmos de la Fábrica de Vesalio, trabajo publicado en $1982^{1}$ y en el que tomaba como base otro so-

\footnotetext{
* El signo ç sustituye el ayin hebreo, por falta de éste en mi ordenador

1 BARCIA GoYANES, J. J. (1982), «Los términos osteológicos de la Fábrica y la evolución del lenguaje anatómico hebreo durante la Edad Media», Sefarad, XLII, 299-325.
} 
bre el mismo tema publicado en 1945 por Mordecai Etziony². En la pág. 305 de mi trabajo copiaba un párrafo del de Mordecai Etziony que rezaba así.

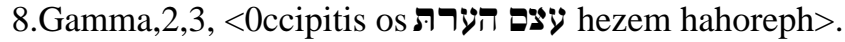

«La transliteración correcta es etzem haoreph. Haoreph significa la parte posterior de la cabeza, por lo tanto etzem haoreph significa el hueso occipital.»

No ha sido éste el significado que de çoref encontramos en la Biblia.

Tal término aparece en el Libro Sagrado 27 veces. Pero solamente 1 en su sentido propio y 26 en el metafórico.

En sentido metafórico lo leemos en Gn.49,8, cuando Jacob, en su lecho de muerte bendice a sus hijos y le dice a Judá: «tu mano pesará sobre el çoref de tus enemigos» que se suele traducir por espalda. Evidentemente quiere decirse aquí que los enemigos de Judá serán derrotados y le volverán la espalda, y aunque aquí se emplee çoref en el original resultaría harto pedante su traducción directa, occipital o atlas como veremos. Me recuerda esta expresión otra que con un sentido muy diferente aparece en Rerum Rusticarum de Marco Terencio Varro que en 1,8,6 nos dice «Ibi dominus simul ac vidit occipitium vendimiatoris». "Allí (en tal viñedo) cuando el amo ve la espalda del vendimiador» se quiere decir metafóricamente «en cuanto el vendimiador se retira «pero si en el latín clásico no resultaba pedante hablar de occipitium en lugar de espalda hoy al traducirlo sería insoportable decir «en cuanto el dueño ve el cogote del vendimiador». También en Job.16,1 3: «me cogió por el çoref y me estrelló». Coger por el cuello a un conejo y arrojarlo lejos no es difícil pero coger por la nuca a un ser humano y realizar la misma maniobra es complicado. Los LXX traducen aquí çoref por ко $\mu \eta$, cabellera. Claro que estaban conscientes de que ésa no era la traducción literal pero seguros de que era una expresión metafórica pensaron que una trenza, sobre todo si caía sobre la espalda, era un excelente asidero para la acción descrita. De estos pasajes no podríamos deducir qué parte del cuerpo se llama çoref, si ya no lo supiésemos. En cambio la tercera cita es muy demostrativa. Se trata de Levítico,5,8, en donde se describe cómo debe proceder el sacerdote que recibe como ofrenda las dos tórtolas o los dos pichones, con los que los pobres podían suplir las víctimas de mayor precio, ovejas o novillos, que debían ofrendar los fieles pudientes. Una de ellas se ofrecía por los pecados propios del oferente y otra en holocausto. Y respecto a aquella, que era la primera que debía ser sacrificada, malaqa etróshó mimul arepo dice el texto hebreo.Es decir: «torcerá con las uñas su cabeza por delante de su çarepo».

2 MordeCAi EtZion, Y. (1945-1946), «The Hebrew-Aramaic Element in Vesalius. A Critical Analysis», Bulletin of the History of Medicine, XVIII, 410-424, y XX, 36-57. 
A la vista de este texto hay que concluir que çoref significa propiamente la primera vértebra cervical o sea el atlas nombre moderno (primeramente usado por Vesalio). No se puede separar la cabeza por delante del occipital como es lo que habría que hacer si llamamos çoref a ese hueso como hace la Academia de la Lengua Hebrea. Y como también lo tradujo Mordecai Etziony en el trabajo que cito al comienzo de este artículo.

Hay otro hecho que habla también en favor de mi traducción. Ni Galeno ni Avicena hablan de huesos del cráneo sino de sus suturas. El árabe llama a la posterior dars al-lamy, es decir, sutura lambda, por su parecido a la letra mayúscula griega. Y esto hacen todos los escritores de esta lengua, a pesar de que disponían de otro nombre genuinamente árabe a قمحدة, qamahduwe. El nombre de sutura lamy pasó a los traductores hebreos del Qanún de Avicena y al texto persa Tashrif-i-mansuri, el primer libro de anatomía en farsi, a caballo de los siglos XIV-XV, aquí ya convertida en hueso del cráneo. En ningún caso se habla de occipucio ni de su traducción por çoref.

Por último, los LXX han traducido el çoref del Levítico por $\sigma \varphi$ ó $v \delta v \lambda$ os, forma arcaica de $\sigma \pi$ ó $v \delta \cup \lambda$ os que vemos en Hipócrates Aforismos, 111,26, en donde se habla de las afecciones de los niños en la vértebra $\tau$ o $\kappa \alpha \tau \dot{\alpha} \tau$ o ívíov. El traductor de la edición de la Classical Library, W. H. S. Jones, traduce estas palabras «the vertebra by the neck» pero creo que es un error ya que para designar al cuello no se diría nunca, «lo que está por debajo del occipital» y así lo pensaron Liddell y Robert que en su traducción de $\sigma \varphi$ ó $v \delta \imath \lambda$ os apuntan que debe de tratarse de la primera vértebra cervical, precisamente apoyándose en el texto hipocrático.

Por supuesto que no pretendo rectificar a Etziony ni mucho menos a la Academia Hebrea de la Lengua. Pero no hay contradicción alguna en que el término çoref haya sido aplicado en el pasado al atlas y lo sea en la actualidad y por las razones que hayan pesado en el ánimo de la A.H. al occipital. De igual manera que hoy llamamos calcáneo al hueso que en otro tiempo y en nuestro idioma se llamó calcañar como vemos en el Diccionario de Autoridades y al astrágalo se le haya llamado taba. El señalar todas las metonimias sería cosa de nunca acabar y yo mismo he publicado un trabajo sobre las sufridas por la túnica dartos ${ }^{3}$. Pero sea una u otra la traducción correcta, lo que es seguro es que no se trata de cerviz. Y esto hube de aprenderlo a mi costa cuando me hallaba preparando mi «Onomatología».

Al disponerme a dar la traducción de cerviz al hebreo me encontré, y ello me sorprendió, con que la Academia Hebrea daba el mismo nombre ducir collum y cervix. Para salir de dudas me dirigí al Prof. A. Ornoy, profesor de Anatomía de la Hadassah Medical School de Jerusalén expresándole mi extrañeza «ante el hecho de que disponiendo la lengua hebrea del término çoref para designar la cerviz, emplease la A.H. con este fin el mismo calificativo que había dado a la

\footnotetext{
3 Barcia Goyanes, J. J. (1984), «Dartos. Una metonimia», Medicina Española, T.83, 277-280.
} 
parte anterior del cuello». Mi colega me contestó amablemente que en la lengua hebrea sólo disponían de la palabra tzawar para designar ambas partes del cuello, ya que çoref significaba occipucio.

Como decíamos al principio çoref sufrió siempre traducciones erróneas. Comenzando por los setenta, éstos buenos conocedores del hebreo emplearon, en su traducción al griego, nada menos que ocho términos diferentes, a saber: $\alpha \cup \chi \eta \dot{\eta} v$ (cuello), $\kappa \alpha \rho \delta i ́ \alpha$ (corazón), $\kappa о \mu \eta$ (cabellera), $v \omega \tau$ ov o $v \omega \tau$ os (espalda), $\sigma \kappa \lambda \eta \rho$ o $\tau \rho \alpha \chi \chi \eta \lambda$ os (cuello duro), $\sigma \varphi$ ó $v \delta \cup \lambda$ os (vértebra). Todos ellos le sirvie-

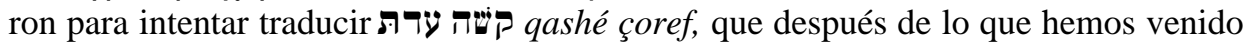
diciendo podemos traducir por nuca dura. Pero aparte de los tres casos que hemos citado, en todos los demás se trataba de una metáfora para señalar la testarudez y contumacia del Pueblo Elegido.

Esa variedad de términos griegos no tuvo semejanza en las traducciones al latín o a las lenguas modernas. Para el primero se habla siempre, a partir de la Vulgata, de populus durae cervicis. Y en las otras se traduce esta expresión. Pueblo de dura cerviz en casi todas las Biblias en castellano, las siguientes citas se hallan tomadas todas de Éxodo 33,3.

He hallado esta expresión en las de Bover, Cantera ${ }^{4}$, Nácar-Colunga ${ }^{5}$, Padres de la Compañía de Jesús ${ }^{6}$, Profesores de Salamanca ${ }^{7}$, Torres Amat ${ }^{8}$, y edición castellana de la Biblia de Jerusalén 9 . Asimismo son equivalentes las expresiones utilizadas en la Biblia danesa ${ }^{10}$ : «du er et hels starrigt volk», la alemana ${ }^{11}$ : «du bist ein halsstarriges Volk», la húngara ${ }^{12}$ : «merk te keméninyakú nép vagy», la francesa ${ }^{13}$ : «peuple au cou roide», la polaca ${ }^{14}$ : «jestes ludem twardego karku», y la rusa: Вьі нароц жестоковьійнийю ${ }^{15}$.

La Biblia polaca habla de lud twardego karku y karku es propiamente «nuca» con lo que nos encontramos con la primera traducción correcta de çoref. También en la

\footnotetext{
4 Bover,J. M., Y CANTERA Burgos, F.(1947), «Sagrada Biblia. Versión Crítica», BAC, 2 tomos.0.

5 NÁCAR, E., Y COLUnGA, A. (1993), Sagrada Biblia. Versión directa de las lenguas originales. 51. ${ }^{\text {a }}$

6 Profesores de la Compañía de Jesús (1968), La Sagrada Escritura. BAC.

7 Profesores de la Universidad de Salamanca (1967), Biblia Comentada, BAC.

TORRES AmAT, F.(1957), Sagrada Biblia, The Grolier Society, New York.

9 UBIETA, J. A. (1967), Biblia de Jerusalem, edición española, Desclée De Brouwer, Bilbao.

Danske Bibelselskab (1986), Bibelen, Kobenhavn.

1 HAMP, V., y STENEEL, M. (1957), Das alte Testament, Aschaffenburg.

2 GÁSPAR, KAROLI (sin fecha), Szent Biblia.

3 SEGOND, L. (sin fecha), La Sainte Bible, Alliance Biblique Universelle.

4 United Bible Societies (1975), Biblia.

5 Russian Bible Societies (1952), Bibliia.
} ed. BAC. 
Biblia árabe ${ }^{16}$ se encuentra la traducción correcta del texto hebreo سمب قساة الرقاب (shaçab qusat ulriqâbi), «pueblo de duro cogote».

Otros autores han preferido prescindir de la metáfora y dan expresiones que traducen el que entienden ser su sentido. Así la Nueva Biblia Española ${ }^{17}$ habla de «pueblo testarudo»; los Monjes de Montserrat ${ }^{18}$ de «poble rebel al jou», la portuguesa ${ }^{19}$ «pobo ostinado», mientras que la Biblia Inglesa ${ }^{20}$ lo llama en Deut.9,6 «stubborn people», pueblo obstinado mientras que en Ex.32,5 lo califica de stiffnecked people, pueblo de cuello rígido, y la gallega de SEPT «pobo que ten a caluga dura» ${ }^{21}$.

En resumen, he pretendido demostrar en este trabajo que las palabras con que, según los autores de los diferentes Libros de la Biblia en que aparece 29 veces la expresión qasheh çoref reprochó Jehová la testarudez del pueblo elegido no han sido las equivalentes a «pueblo de dura cerviz» sino las de «pueblo de cabeza dura», tanto si traducimos çoref por occipital como si preferimos hacerlo por «hueso de la nuca».

Y se comprende que así tenía que ser. Porque ¿qué relación existe entre el cuello y la testarudez?.

Cuando por vez primera me enfrenté a la expresión que nos ha ocupado pensé que tal vez se trataba de la desviación hacia el hombre de un vicio que los primitivos hebreos habrían descubierto en algunos camellos. Tales animales no son manejados de la misma manera que los caballos de silla. Como es sabido, a éstos se les coloca una cabezada que sostiene el bocado o el filete los cuales se apoyan en la zona de la mandíbula desprovista de dientes de tal suerte que al tirar de la rienda la presión obliga al caballo a torcer el cuello. Por ello llamamos duros de boca a los caballos que se resisten a obedecer la indicación del jinete.

Por el contrario los camellos llevan una soga enrollada alrededor del hocico, tirando de la cual se pretende obligar al animal a torcer el cuello. Si el animal se niega hay poco que hacer ya que el dolor producido por la cuerda es escaso. En todo caso se comprende que si se niega digamos que tiene el cuello duro. Recuerdo que pregunté a mi admirado y llorado amigo J. Leibowitz si no sería esta circunstancia la que originó la expresión duro de cerviz, pero me contestó negativamente. Y es que para él no existía tal expresión. Pensaba en hebreo y por ello para él la frase existente era duro de cogote o duro de cabeza, cabezota.

En ningún idioma, al menos en los que conozco se pone en relación el cuello con sentimientos anímicos. Por el contrario sí se piensa en la cabeza.

16 Büiblia Arabe (católica) (1960), Beirut.

17 SCHÖKEL, L. A., y MATOS, J. (1975), Nueva Biblia Española, Cristandad, Madrid.

18 Monjes de Montserrat (1983), Biblia, versión catalana, 3. ${ }^{a}$ ed.

19 Ferreira de Almeida, J. (1968), A Bíblia Sagrada, Lisboa.

20 The Bible Societies (1971), The Holy Bible, New York.

21 SEPT (1989), A Biblia. 
Así lo vemos en francés, têtu (de tête) es antiguo. Lo cita Du Cange de la obra Le Martyr de St. Paul, del siglo XV: «Saule, Saule trop es testu. Dy pourquoi me guerroies tu?»

En castellano testa, que sustituyó a caput, da lugar a testarudo. Testardo es el equivalente italiano. Y en alemán el equivalente starrköpfig y hardheaded el inglés, el stijhofd holandés, el tjurhavud sueco, el valenciano caparut. Las citas podrían prolongarse hasta llenar páginas enteras. 